\title{
Some ice nucleation characteristics of Asian and Saharan desert dust
}

\author{
P. R. Field ${ }^{1, *}$, O. Möhler ${ }^{2}$, P. Connolly ${ }^{3}$, M. Krämer ${ }^{4}$, R. Cotton ${ }^{1}$, A. J. Heymsfield ${ }^{5}$, H. Saathoff ${ }^{2}$, and M. Schnaiter ${ }^{2}$ \\ ${ }^{1}$ Met Office, Exeter, UK \\ ${ }^{2}$ Institute for Meteorology and Climate Research (IMK-AAF), Forschungszentrum Karlsruhe, Germany \\ ${ }^{3}$ School of Earth, Atmospheric and Environmental Sciences, University of Manchester, Manchester, UK \\ ${ }^{4}$ Institute of Chemistry and Dynamics of the Geosphere (ICG-I), Forschungszentrum Jülich, Germany \\ ${ }^{5} \mathrm{NCAR}$, Boulder, CO, USA \\ *now at: NCAR, Boulder, CO, USA
}

Received: 5 December 2005 - Published in Atmos. Chem. Phys. Discuss.: 23 February 2006

Revised: 23 May 2006 - Accepted: 19 June 2006 - Published: 21 July 2006

\begin{abstract}
The large $\left(7 \mathrm{~m} \times 4 \mathrm{~m}\right.$ cylinder, $\left.84 \mathrm{~m}^{3}\right)$ AIDA (Aerosol Interactions and Dynamics in the Atmosphere) cloud chamber facility at Forschungszentrum, Karlsruhe, Germany was used to test the ice nucleating ability of two desert dust samples from the Sahara and Asia. Aerosol samples were lognormally distributed with a mode diameter of $0.4( \pm 0.1) \mu \mathrm{m}$ and geometric standard deviation of $\sim 1.7( \pm 0.2)$. At temperatures warmer than $-40^{\circ} \mathrm{C}$ droplets were formed before ice crystals formed and there was generally no deposition nucleation observed. At temperatures colder than $-40^{\circ} \mathrm{C}$ both dust samples exhibited dual nucleation events that were observed during the same expansion experiment. The primary nucleation event occurred at ice saturation ratios of 1.1 to 1.3 and is likely to be a deposition nucleation mode. The secondary nucleation event occurred at ice saturation ratios between 1.35 and 1.5. We cannot categorically determine whether this ice nucleation event is via a further deposition mode or a condensation mode, but the presence of some soluble material in the dust samples leads us to favour the latter process. The activated fractions of desert dust ranged from $\sim 5-10 \%$ at $-20^{\circ} \mathrm{C}$ to $20-40 \%$ at temperatures colder than $-40^{\circ} \mathrm{C}$. There was no obvious difference between the nucleation behaviour of the two dust samples.
\end{abstract}

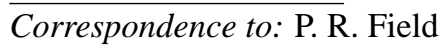

(prfield@ucar.edu)

\section{Introduction}

The nucleation of ice crystals can proceed via a number of different pathways (e.g. Vali, 1985; Pruppacher and Klett, 1997; Cantrell and Heymsfield, 2005). The main nucleation mechanisms are commonly referred to as (following Vali, 1985) i) homogeneous nucleation - the formation of ice through the random motions of water molecules becoming arranged as an ice embryo. This mechanism is highly temperature dependent and in the atmosphere is not important for clouds warmer than $-38^{\circ} \mathrm{C}$. ii) Deposition nucleation the formation of ice by vapour deposition directly onto the surface of insoluble ice nuclei. These nuclei are thought to originate mainly from crustal sources (e.g. desert dust), biomass burning or industrial processes (e.g. soot or metals). iii) Condensation freezing - this process involves the activation of a liquid droplet on a condensation nucleus that acts to freeze the droplet during the condensation stage. iv) Immersion freezing - an insoluble ice nucleus suspended within a supercooled droplet causes the droplet to freeze. v) Contact freezing - this process again requires a liquid droplet to be activated whose surface then subsequently comes into contact externally, or internally (Durant and Shaw, 2005), with an insoluble ice nucleus that causes the droplet to freeze. Pruppacher and Klett (1997) additionally state that immersion freezing occurs through the action of the ice nucleus as a cloud condensation nucleus at temperatures above $0^{\circ} \mathrm{C}$ which subsequently causes the droplet to freeze when it is cooled below $0^{\circ} \mathrm{C}$. In contrast, the sequence of events for condensation freezing all occur at temperatures colder than $0^{\circ} \mathrm{C}$. In the experiments presented here we will never activate a droplet

Published by Copernicus GmbH on behalf of the European Geosciences Union. 
at temperatures above $0^{\circ} \mathrm{C}$, and so we will refer to droplet freezing events where we do not believe homogeneous freezing is responsible as simply condensation or contact freezing.

The role of desert dust in ice nucleation has recently been characterized in the Caribbean during the CRYSTAL-FACE (Cirrus Regional Study of Tropical Anvils and Cirrus Layers - Florida Area Cirrus Experiment, Jensen et al., 2004) campaign when Saharan dust advected across the Atlantic into the field area (Sassen et al., 2003; DeMott et al., 2003; Cziczo et al., 2004; Twohy and Poellot, 2005). Desert dust is known to act as good deposition nuclei (e.g. Isono, 1953; Roberts and Hallett, 1968) but other nucleating properties associated with desert dust are not well characterized. DeMott et al. (2003) reported on ice nuclei measurements in a Saharan dust plume observed during the CRYSTAL-FACE experiment. They found at $-36.5^{\circ} \mathrm{C}$ and a supersaturation with respect to ice of $23 \%$ that they observed $\sim 1 \mathrm{~cm}^{-3}$ ice nuclei concentrations. Coincident aerosol concentrations for sizes greater than $0.5 \mu \mathrm{m}$ were $\sim 10 \mathrm{~cm}^{-3}$. It is likely that the aerosol concentrations were higher, but even assuming background aerosol concentrations of $10 \mathrm{~cm}^{-3}$ gives an upper limit for ice nucleation efficiency of 0.1. These conditions are below water saturation and so these observations represent the concentration of deposition nuclei.

During the same campaign Sassen et al. (2003) presented evidence suggesting that altocumulus clouds $\left(-5\right.$ to $\left.-8^{\circ} \mathrm{C}\right)$ were being glaciated through interaction with the Saharan dust either via an immersion/condensation or contact nucleation process. Cziczo et al. (2004) showed that mineral dust was the dominant residue (nuclei on which the ice formed) during that event found after in-situ ice particles were captured and evaporated using a Counterflow Virtual Impactor (CVI). Twohy and Poellot (2005) analysed data from many flights during the campaign and showed that the fractional composition of non-volatile ice residuals sampled with a CVI and ambient aerosol were remarkably similar. Comparison of the amount of soluble (salts) to insoluble residual material (metals and crustal) as a function of temperature suggested that homogeneous nucleation dominated at temperatures colder than $-39^{\circ} \mathrm{C}$. Metals and crustal material residuals were found in comparable amounts for the small residuals, but the metals were almost twice as prevalent in the larger residuals. Analysis of CVI residuals (Targino et al., 2005) from the INTACC (INTeraction of Aerosol and Cold Clouds) experiment (Field et al., 2001) showed that mineral dust is more prevalent in the cases where heterogeneous ice nucleation was observed to be active.

Previous laboratory work on the ice nucleating ability of kaolinite has been carried out by Roberts and Hallett (1968). They found for freshly prepared samples that supersaturations with respect to ice of $20 \%$ at temperatures colder than $-18^{\circ} \mathrm{C}$ were required for the kaolinite to act as ice nuclei. Following the formation of ice they raised the temperature slightly to drive off the ice and repeated the experiment. They found that kaolinite particles that had previously formed ice crystals now activated at $10 \%$ supersaturation with respect to ice, suggesting that ageing could produce more efficient ice nuclei. More recently, Bailey and Hallett (2002) have nucleated ice on glass filaments coated with kaolinite at temperatures up to $-12^{\circ} \mathrm{C}$ and $12 \%$ supersaturation with respect to ice. In contrast, Salam et al. (2006) used commercially available mineral dust particles and found that warmest temperature at which kaolinite particles with a mean diameter of $1 \mu \mathrm{m}$ formed ice was $-22^{\circ} \mathrm{C}$ and $23 \%$ supersaturation with respect to ice, which is very close to water saturation. Salam et al. (2006) also examined the behaviour of montmorillonite and found for a similar size distribution of test particles that the warmest temperature at which it would form ice was $-15^{\circ} \mathrm{C}$, but the required supersaturation was only $9 \%$ with respect to ice.

Recently, Zuberi et al. (2002) looked at the formation of ice on aqueous droplets $\left(\left(\mathrm{NH}_{4}\right)_{2} \mathrm{SO}_{4}-\mathrm{H}_{2} \mathrm{O}, 10-50 \mu \mathrm{m}\right.$ in size) containing dust particles. They found that for significant mass fractions of dust ( $>27 \%$ ) that the droplets froze at much lower saturations than would be expected for homogeneous freezing of a droplet without any dust inclusion. Similarly, Hung et al. (2003) showed that mineral dust inclusions increased the temperature at which ice nucleation occurs.

The indirect effects of ice nuclei that include the impact on cloud albedo and cloud lifetime by changing the mean size and/or the phase of the particles have been investigated using global climate models (Lohmann and Feichter, 2005). Lohmann and Kärcher (2002) find that anthropogenically produced aerosol has little effect on the formation and maintenance of cirrus for temperatures colder than $-35^{\circ} \mathrm{C}$ where homogeneous nucleation dominates. At warmer temperatures where heterogeneous ice nucleation processes dominate, the effects on cloud albedo, lifetime, and precipitation are likely to be more profound (Lohmann and Feichter, 2005). Large fractions of the upper troposphere are supersaturated with respect to ice (Gettelman et al., 2006). If deposition ice nuclei become more prevalent then this could lead to increased cloudiness, although it is difficult to predict what the outcome of increasing the concentrations of ice nuclei will be in a system with cloud feedbacks of undetermined sign (e.g. Stocker et al., 2001). These results suggest that the role of desert dust in the evolution of clouds and precipitation may be important and provide motivation for the present study reported here and in a companion paper (Möhler et al., 2006).

In this paper we report on a series of laboratory experiments carried out at the AIDA cloud and aerosol chamber facility in which two desert dust samples were tested under realistic atmospheric conditions and in relatively large numbers. This paper focuses on the results for the desert dust samples that formed ice at temperatures between $-55^{\circ} \mathrm{C}$ and $-20^{\circ} \mathrm{C}$ emphasising observations made with the Small Ice Detector that is capable of determining the phase of particles. The companion paper by Möhler et al. (2006) deals with the ice nucleation events that occurred in the $-80^{\circ} \mathrm{C}$ to $-50^{\circ} \mathrm{C}$ 
temperature range. That paper contains extensive information concerning the accuracy of the various measurements within the chamber and the methods employed in analysis of the dust samples, that is precised in this text.

In Sect. 2 the basic experimental procedure is outlined. In Sect. 3 the dust samples are described. In Sect. 4 the instrumentation used is described. Section 5 is a presentation of the results and Sects. 6 and 7, respectively, contain the discussion and conclusions.

\section{Experimental procedure}

The cylindrical AIDA aerosol vessel is $7 \mathrm{~m}$ high and $4 \mathrm{~m}$ in diameter $\left(84 \mathrm{~m}^{3}\right)$. The aerosol vessel is located within a larger chamber that acts as a thermal buffer and provides control of the initial temperature within the aerosol vessel. A fan within the aerosol vessel ensures well mixed conditions with sample temperatures within the volume varying by $\pm 0.2 \mathrm{~K}$.

Ice nucleation experiments are started just below ice saturation inside the aerosol vessel. At the start of the experimental series the inside walls of the aerosol vessel are coated with ice. Before each aerosol sample is added the vessel is evacuated to $0.01 \mathrm{hPa}$ and flushed twice with synthetic air. Next, water vapour and synthetic air are added to bring the vessel to atmospheric pressure. Finally, the temperature of the vessel is brought to the starting temperature of the experiment.

To simulate the adiabatic cooling of rising air parcels the pressure within the chamber is reduced with a rate controllable mechanical pump from $1000 \mathrm{hPa}$ to $800 \mathrm{hPa}$ over typical pumping periods of $5 \mathrm{~min}$. Mean cooling rates (close to the time of nucleation) for the experiments presented here were typically $1-2 \mathrm{~K} \mathrm{~min}^{-1}$ that is equivalent to ascent speeds of $2.5-5 \mathrm{~m} \mathrm{~s}^{-1}$ (for a $-6.5 \mathrm{~K} \mathrm{~km}^{-1}$ lapse rate). Such ascent rates can be found in orographic wave clouds and modest cumulus clouds, but are slightly on the high side for stratiform clouds. The cooling in the aerosol vessel is not purely adiabatic: the aerosol vessel wall temperatures remain approximately constant throughout the expansion and as a consequence there is a heat flux from the vessel wall into the chamber. Similarly, during the cooling the vapour pressure above the ice on the wall is greater than the vapour pressure in the chamber and a vapour flux into the chamber also occurs.

Before the candidate aerosol is added to the chamber a control run is made with the background conditions in the chamber. Once complete the candidate aerosol is added and then characterized with standard aerosol sampling intrumentation. Several expansions are carried out on the same candidate aerosol sample at different pump speeds (cooling rates) throughout the course of a day. Typically, during each series of 3 or 4 expansions, the first two expansions were done at the same higher cooling rate than the subsequent expansions.
More details about the AIDA chamber and the experimental procedures can be found in Möhler et al. $(2003,2006)$.

\section{Dust samples}

Two surface samples of desert dust obtained from Asia (AD1) (Takla Makan Desert, China) and the Sahara (SD2) (near Cairo, Egypt) were used. Prior to the experiment the samples were stored in clean conditions and did not undergo any heating or crushing. X-ray fluorescence mass fraction analysis of bulk samples (diameter $<20 \mu \mathrm{m}$ ) indicated that the Asian and Saharan dust samples were rich in silicon and calcium oxides, respectively, while both samples had similar fractions of aluminium oxide. This result is suggestive of the presence of silicates and quartz within the samples. Additionally, ion chromatography showed that the soluble mass fraction of bulk dust samples was $<1 \%$. It should be noted that the mass fraction analyses carried out on these samples was weighted towards particles larger than those that were used in the ice nucleation experiments, and therefore it is possible that the chemical and mineralogical composition of the smaller particles used in the experiments differed from the bulk results.

For the nucleation experiments, the samples were dry redispersed and fed into the aerosol vessel producing approximately log-normal aerosol distributions with a size range between 0.1 and $2 \mu \mathrm{m}$ and mode diameters between 0.3 and $0.5 \mu \mathrm{m}$. Möhler et al. (2006) gives more information concerning the results of X-ray analysis, aerosol distributions and redispersion methodology.

\section{Instrumentation}

The AIDA chamber is populated with many instruments (see Möhler et al., 2003, 2006), but we will briefly describe only the instrumentation referred to in this paper. Measurement accuracies for the various instruments employed are gathered together in Table 1.

The temperature of the gas and wall of the chamber is measured at multiple locations with platinum resistance thermometers and thermocouples. These values are combined and an average gas temperature is computed. Pressure is measured with high precision Baratron sensors (MKS, Munich). An in situ multi-reflection path tunable diode laser absorption spectrometer directly measures the the water vapour concentration in the chamber volume. The TDL water vapour concentration is scaled to match a cryogenically cooled mirror hygrometer (LX373, MBW ,Switzerland) that is accurate to better than $\pm 0.1 \mathrm{~K}$ during the expansion phase before any condensate appears. The sample air for the humidity sensors is obtained through an $8 \mathrm{~mm}$ diameter inlet heated to $30^{\circ} \mathrm{C}$ located near the top of the chamber. Once particles are produced they will be ingested and evaporated as they enter the humidity measurement system. This effect 
Table 1. Measurement errors (1 Hz).

\begin{tabular}{|c|c|c|}
\hline Measurement & Random measurement error $(1 \mathrm{~Hz})$ & Notes \\
\hline Thermal box temperature & $\pm 0.3 \mathrm{~K}$ & \\
\hline Aerosol vessel temperature variation & $\pm 0.2 \mathrm{~K}$ & when stirred \\
\hline Aerosol vessel wall temperature & $\pm 0.3 \mathrm{~K}$ & \\
\hline Aerosol vessel gas temperature & $\pm 0.3 \mathrm{~K}$ & \\
\hline Initial relative humidity & $\pm 3 \%$ & due to $\pm 0.2 \mathrm{~K}$ temperature variation \\
\hline MBW frostpoint & $\pm 0.1 \mathrm{~K}$ & \\
\hline TDL vapour pressure & $\pm 1 \% @ 250 \mathrm{~K}, \pm 1.3 \% @ 220 \mathrm{~K}, \pm 1.7 \% @ 190 \mathrm{~K}$ & after scaling to match MBW \\
\hline Relative humidity & $\pm 3 \% @ 250 \mathrm{~K}, \pm 4 \% @ 220 \mathrm{~K}, \pm 6 \% @ 190 \mathrm{~K}$ & combined TDL error and gas temperature error \\
\hline TSI CPC 3010 concentration & $\pm 10 \%$ & Size detection range $10 \mathrm{~nm}-3 \mu \mathrm{m}$ diameter \\
\hline Optical particle counter WELAS concentration & $\pm 10 \%$ & detects dust $>0.5 \mu \mathrm{m}$, ice $>0.8 \mu \mathrm{m}$ \\
\hline SID concentration & $\pm 20 \%$ & Size detection range $1-35 \mu \mathrm{m}$ diameter. \\
\hline
\end{tabular}

results in the humidity measurement containing some contribution from the condensed water content. As the particles grow larger their collection efficiency by the humidity system decreases and the contribution from particles is difficult to quantify. Hence when condensed water contents are high the total water measurement can become unreliable. Combining the uncertainties in the temperature and water vapour concentration provides an estimate of the uncertainty in the 1-s humidity measurement of $\pm 3-4 \%$ for the temperature and humidity range considered here.

Particles are detected and measured with the Small Ice Detector (SID, University of Hertfordshire, UK) and Cloud Particle Imager (CPI: Stratton Park Engineering Company, SPEC Inc). These two probes were primarily designed to sample particles from aircraft, but can be used in the laboratory. Aerosol concentrations were measured with a CPC3010 (TSI) optical particle counter. In some cases the aerosol data was not available and so we made use of the Welas probe (Palas Aerosol Technology, Germany).

The hypothesis that liquid droplets are spherical and ice crystals are not spherical is the basis of the phase determination method used by the SID probe. The SID is a laser scattering device that can count and size spherical particles between 1 and $35 \mu \mathrm{m}$ (diameter) and count non-spherical particles. The probe uses six detectors arranged azimuthally at a forward scattering angle of $30^{\circ}$, with a seventh detector mounted at the forward scattering angle. One of the six $30^{\circ}$ detectors has an iris fitted to allow it to define a $400 \times 800 \mu \mathrm{m}$ ellipse on the scattering laser. When light was detected by this detector and one other detector, a particle was known to be in the sample volume and the detector responses were recorded. By comparing the responses of the azimuthally arranged detectors an "asphericity factor" $(A f)$ could be obtained for each particle measured that ranges from 0 for spherical particles to 100 for very non-spherical particles (see Hirst et al., 2001 for more details). The five $30^{\circ}$ detectors that were not stopped down with the iris were used to compute $A f$ using:
$A f=k \frac{\sqrt{\sum_{i=1}^{5}\left(<E>-E_{i}\right)^{2}}}{<E>}$,

where $k$ is a constant $(=22.361)$ set to place $A f$ in the range $0-100, E_{i}$ are the detector values and $\langle E>$ is the mean of $E_{i}$. In practice, noise and differences between the detectors mean that the spherical droplets that should give $A f=0$ will in general produce non-zero values. Single particles must therefore be differentiated from ice by using a threshold value for the asphericity. Using a threshold can lead to some non-spherical particles being classed as spherical and viceversa. Field et al. (2004) assessed the choice of $A f$ threshold values by sampling stratocumulus clouds warmer than $0^{\circ} \mathrm{C}$ where only liquid droplets would be found and synoptically generated cirrus colder than $-40^{\circ} \mathrm{C}$ where only ice crystals are expected to be found. These two datasets indicate that if an $A f$ value of 12 is used to threshold the particles into spherical and non-spherical then $10 \%$ are mis-classified. From intercomparison with other aircraft probes the uncertainty in $1 \mathrm{~Hz}$ concentration is estimated to be $\sim 20 \%$. The lowered count rates encountered in the laboratory setting will also result in a non negligible Poisson counting error. The SID probe sampled horizontally from near the base of the chamber with an estimated flow speed of $\sim 5 \mathrm{~m} \mathrm{~s}^{-1}\left(\sim 1 \mathrm{~cm}^{3}\right.$ sampled per second). Intercomparison with other probes in the AIDA chamber (see Möhler et al., 2006) indicated that this flow speed may have been underestimated and so the SID concentrations calculated using the $5 \mathrm{~m} \mathrm{~s}^{-1}$ flow speed were multiplied by 1.6. This laboratory flow speed is very different from aircraft speeds so appropriate scaling of the calibration constants for sizing were applied based on the increased time-of-flight through the probe detection volume. Particle sizing from this instrument assumes that the particle is spherical. Therefore, non-spherical particles will be incorrectly sized, but this "spherical diameter" can still be used qualitatively to assess if ice particles are growing. In the following analysis, results are accumulated over $10 \mathrm{~s}$ for estimating the activated fraction and so, given the sampling rate, this sets a concentration detection limit of $\sim 0.1 \mathrm{~cm}^{-3}$. 
The CPI is a 2-D imaging probe designed to take high resolution images of cloud ice crystals and large droplets. It has two particle detection lasers which intercept at the probes sample area (located within the probes air sampling tube at the focal plane of an objective lens; the images are magnified using a Galilean telescope arrangement) and fall onto a photomultiplier dump spot. Once particles are detected with the particle detection lasers/photomultipliers a high power, $20 \mathrm{~ns}$ pulsed laser is armed which is directed through the sample area, falling onto a charge coupled device (CCD) camera, which consequently images the shadow of the particle. Since the distance of the particle from the object plane is comparable to the size of the particle, the images are well described by the Fresnel-Kirchhoff diffraction theory, which is the basis for the correction of probe sample volume and particle size. The CPI is able to sample particles within the size range of approximately 10 to 2000 microns. Sampling efficiency decreases as particle size decreases from 20 microns as a threshold shadow depth is required for detection. The depth of field of the particle is constrained so that the images are not in poor focus. The limitations of the probe are discussed in Connolly et al. (2006) ${ }^{1}$. Image processing techniques are applied to the particle images, so that particles can be sized, and classified into droplets, or numerous ice particle habits. When particle size increases above $400 \mu \mathrm{m}$, the sampling efficiency drops off gradually due to the fact that the overlapping cross section of particles with the sample area decreases.

The Welas particle probe uses white light scattering collected at $90 \pm 12^{\circ}$ scattering angle from a sample volume defined by an apertured light source to measure particles in the size range 0.8 to $46 \mu \mathrm{m}$ (for water droplets).

\section{Results}

\subsection{Time series}

We present four time series to demonstrate the ice nucleation behavior of the dust samples at different temperatures. Three examples result from using the Asian dust sample and one from the Saharan dust sample. The features of the ice nucleation that we will highlight using either the Asian or Saharan sample are seen for both of these dust samples at the same temperature.

Each time series figure comprises of 6 panels showing 1-s data as a function of time since the start of pumping. Panel (a) shows the pressure forcing and temperature change imposed in the AIDA cloud chamber. Panel (b) gives the saturation ratio with respect to water and ice throughout the

\footnotetext{
${ }^{1}$ Connolly, P. J., Flynn, M. J., Ulanowski, Z., Ibbottson, T., Gallagher, M. W., and Choularton, T. W.: Calibration of 2-D imaging probes using calibration beads and ice crystal analogues part 1: The depth-of-field, J. Tech., in review, 2006.
}

experiment. Panel (c) is a plot of the SID asphericity parameter, $A f$, with each point representing a single particle measurement. In panel (d) various concentrations are depicted (5-s smoothing): The total SID concentration, the concentration of SID particles with $A f>12$ (non-spherical particles), the concentration of SID particles with "spherical diameter" $>3 \mu \mathrm{m}$ and the CPI concentration (diameter $>10 \mu \mathrm{m}$ ). Panel (e) shows single particle measurements of SID particle "spherical diameter" and a contour plot of the CPI size distribution to provide the reader with a qualitative indication of when larger ice particles are present. Finally, panel (f) shows the activated fraction of ice particles defined by the concentration of particles with 10-s binned $A f>12$ compared to the instantaneous aerosol concentration defined by the (initial aerosol concentration $\times$ pressure)/(initial pressure). Running vertically throughout the figure are dotted lines that indicate when the fraction activated nominally exceeds $0.5 \%$ and $8 \%$ and when the concentration of SID particles with "spherical diameter" $>3 \mu \mathrm{m}$ exceeds $0.4 \%$ of the instantaneous aerosol concentration. The 10-s binning means that the activation thresholds may have been exceeded up to $5 \mathrm{~s}$ earlier. This potential systematic error translates to a temperature underestimate of less than $0.2 \mathrm{~K}$ and corresponding humidity underestimate of up to $\sim 2 \%$. Ice concentrations were determined by the SID concentration of non-spherical particles $(A f>12)$. Because the determination of particle sphericity can lead some particles to be classified as spherical, the concentration of ice crystals using this criteria could be underestimated by $10 \%$. We also note here that there may be some time delay between ice particles nucleating and their subsequent detection with SID. Möhler et al. (2006) have attempted to estimate this delay by invoking a simple growth model. Such an approach is more difficult to apply when we are considering the shape as well as the size of the particles and may not be necessary at the relatively warm temperatures considered here: Möhler et al. estimate a delay of $4 \mathrm{~s}$ for the growth to $\sim 1 \mu \mathrm{m}$ at $-50^{\circ} \mathrm{C}$, the coldest temperatures presented in this paper. Nevertheless, this difference in approach to estimating the onset of nucleation leads to slight differences in conditions at which the nucleation is observed, but still within the estimated experimental errors. Various parameters relating to the ice nucleation events are given in Table 2. Example CPI imagery from these experiments can be seen in Fig. 5 .

Figure 1 shows one example from the coldest series of ice nucleation events sampled with the SID probe. Run 29 (AD1) starts at $-51^{\circ} \mathrm{C}$ and is cooled to $-57^{\circ} \mathrm{C}$ over $\sim 400 \mathrm{~s}$. Around $0 \mathrm{~s}$ the background aerosol that can be detected by SID can be seen in panel (e). This aerosol generally has a "spherical diameter" $<3 \mu \mathrm{m}$ for all of the experiments and we use this as a threshold size between activated particles and aerosol. At $50 \mathrm{~s}$ panel (e) shows a rapid increase in the size of particles, panel (d) indicates increases in SID concentrations and panel (c) shows the abrupt appearance of particles with Af values greater than 12 . At $250 \mathrm{~s}$ there is another burst of 
Table 2. Ice nucleation exceeding active fraction thresholds of 0.5 and $8 \%$. Horizontal lines divide up each suite of experiments that used the same aerosol sample for repeated expansions.

\begin{tabular}{|c|c|c|c|c|c|c|c|c|c|}
\hline Exp & $\begin{array}{l}\text { Temperature } \\
\mathrm{C}\end{array}$ & $\begin{array}{l}>0.5 \% \\
\text { Pressure } \\
\mathrm{mb}\end{array}$ & $\begin{array}{l}\text { Saturation } \\
\text { Ratio }\end{array}$ & $\begin{array}{l}\text { Temperature } \\
\mathrm{C}\end{array}$ & $\begin{array}{l}>8 \% \\
\text { Pressure } \\
\mathrm{mb}\end{array}$ & $\begin{array}{l}\text { Saturation } \\
\text { Ratio }\end{array}$ & $\begin{array}{l}\text { Max. act. } \\
\text { Fraction }\end{array}$ & $\begin{array}{l}\text { Initial aerosol } \\
\text { Concentration } \\
\mathrm{cm}^{-3}\end{array}$ & Sample \\
\hline 18 & -29.4 & 829 & 1.30 & -30.1 & 796 & 1.29 & 0.09 & 215 & AD1 \\
\hline 19 & -30.2 & 844 & 1.31 & -31.4 & 806 & 1.31 & 0.14 & 152 & AD1 \\
\hline 20 & -32.0 & 846 & 1.36 & -31.8 & 836 & 1.28 & 0.11 & 105 & AD1 \\
\hline 21 & -33.4 & 856 & 1.38 & -33.5 & 838 & 1.32 & 0.11 & 75 & AD1 \\
\hline 22 & -40.5 & 900 & 1.30 & -42.2 & 845 & 1.38 & 0.15 & 139 & AD1 \\
\hline 23 & -41.2 & 892 & 1.30 & -42.6 & 839 & 1.42 & 0.17 & 94 & AD1 \\
\hline 24 & -41.3 & 892 & 1.27 & -42.7 & 855 & 1.39 & 0.33 & 68 & AD1 \\
\hline 25 & -40.4 & 901 & 1.12 & - & - & - & 0.06 & 45 & AD1 \\
\hline 26 & -52.7 & 972 & 1.17 & -53.9 & 950 & 1.31 & 0.28 & 119 & $\mathrm{AD} 1$ \\
\hline 27 & -53.4 & 958 & 1.22 & -55.0 & 924 & 1.43 & 0.30 & 72 & AD1 \\
\hline 28 & -53.0 & 963 & 1.14 & -55.7 & 893 & 1.46 & 0.19 & 44 & AD1 \\
\hline 29 & -53.2 & 953 & 1.14 & -55.9 & 875 & 1.48 & 0.33 & 29 & $\mathrm{AD} 1$ \\
\hline 30 & -21.6 & 951 & 1.22 & - & - & - & 0.06 & 353 & SD2 \\
\hline 31 & -21.1 & 952 & 1.20 & - & - & - & 0.03 & 150 & SD2 \\
\hline 32 & -19.7 & 973 & 1.03 & - & - & - & 0.08 & 24 & $\mathrm{SD} 2$ \\
\hline 35 & -38.0 & 928 & 1.43 & -38.3 & 921 & 1.46 & 0.20 & 153 & SD2 \\
\hline 36 & -38.5 & 923 & 1.42 & -38.8 & 915 & 1.41 & 0.45 & 88 & SD2 \\
\hline 37 & -36.1 & 963 & 1.15 & -38.7 & 907 & 1.42 & 0.69 & 38 & SD2 \\
\hline 40 & -51.7 & 945 & 1.25 & -53.1 & 917 & 1.41 & 0.20 & 107 & SD2 \\
\hline 41 & -52.0 & 941 & 1.26 & -53.6 & 899 & 1.46 & 0.21 & 64 & SD2 \\
\hline 42 & -51.5 & 955 & 1.17 & -53.9 & 895 & 1.50 & 0.36 & 39 & SD2 \\
\hline
\end{tabular}

ice particle production visible in panel (e) as a second branch of increasing SID particle size. This is accompanied by a step increase in SID concentrations shown in panel (d). The particle concentrations then remain fairly constant until the humidity falls below ice saturation. The two ice nucleation events occur at supersaturation with respect to ice of $10 \%$ and $50 \%$ and activate $\sim 5 \%$ and $\sim 30 \%$ of the aerosol, respectively. CPI imagery for this experiment in Fig. 5 shows rosette-like habits.

Figure 2 is for run $24(\mathrm{AD} 1)$ which began at $-36^{\circ} \mathrm{C}$ and cooled to $-44^{\circ} \mathrm{C}$ after $270 \mathrm{~s}$. As in the previous case it is possible to discern two ice nucleation events. One occurs at 70 s marked by the growth of a few ice particles in panel (e) and then a more obvious second event at $150 \mathrm{~s}$ that is close to water saturation $(\sim 95 \%)$. Variability of the humidity and temperature fields within the chamber could result in regions at water saturation. If so, then any droplets produced were either not sampled by the SID or smaller than $\sim 3 \mu \mathrm{m}$ in diameter. This figure exemplifies the difficulties in determining the onset of ice nucleation. The CPI concentration in panel (d) supports the suggestion that there is a nucleation event before the one at $150 \mathrm{~s}$, identified by the growth of par- ticles measured by SID. As in the previous example the activated fraction of aerosol from the primary and secondary nucleation events is $\sim 5 \%$ and $\sim 30 \%$. CPI imagery for this experiment in Fig. 5 again shows rosette-like habits. The noise seen in the humidity signal is probably the result of attenuation of the signal light source in the TDL system by condensed water.

Figure 3 is from run 20 (AD1) and appears different to the previous two examples. The run began at $-23^{\circ} \mathrm{C}$ and was cooled to $-32^{\circ} \mathrm{C}$ over $110 \mathrm{~s}$. In this case it can be seen that at $100 \mathrm{~s}$ there is a rapid production of large numbers of particles (panel d). Referring to the asphericity parameter in panel (c) suggests that from $100 \mathrm{~s}$ to $150 \mathrm{~s}$ the cloud is dominated by water droplets (asphericity values $<12$ ). Looking at the concentration of non-spherical particles and CPI concentration (panel d) as well as the particle sizes (panel e) indicates that ice particles were present almost coincidently with the formation of droplets, but not before. This suggests that the dominant ice nucleation mode in this case is a condensation mechanism or possibly contact freezing, although the short timescales involved probably preclude the action of contact freezing. Such an assertion remains to be tested 


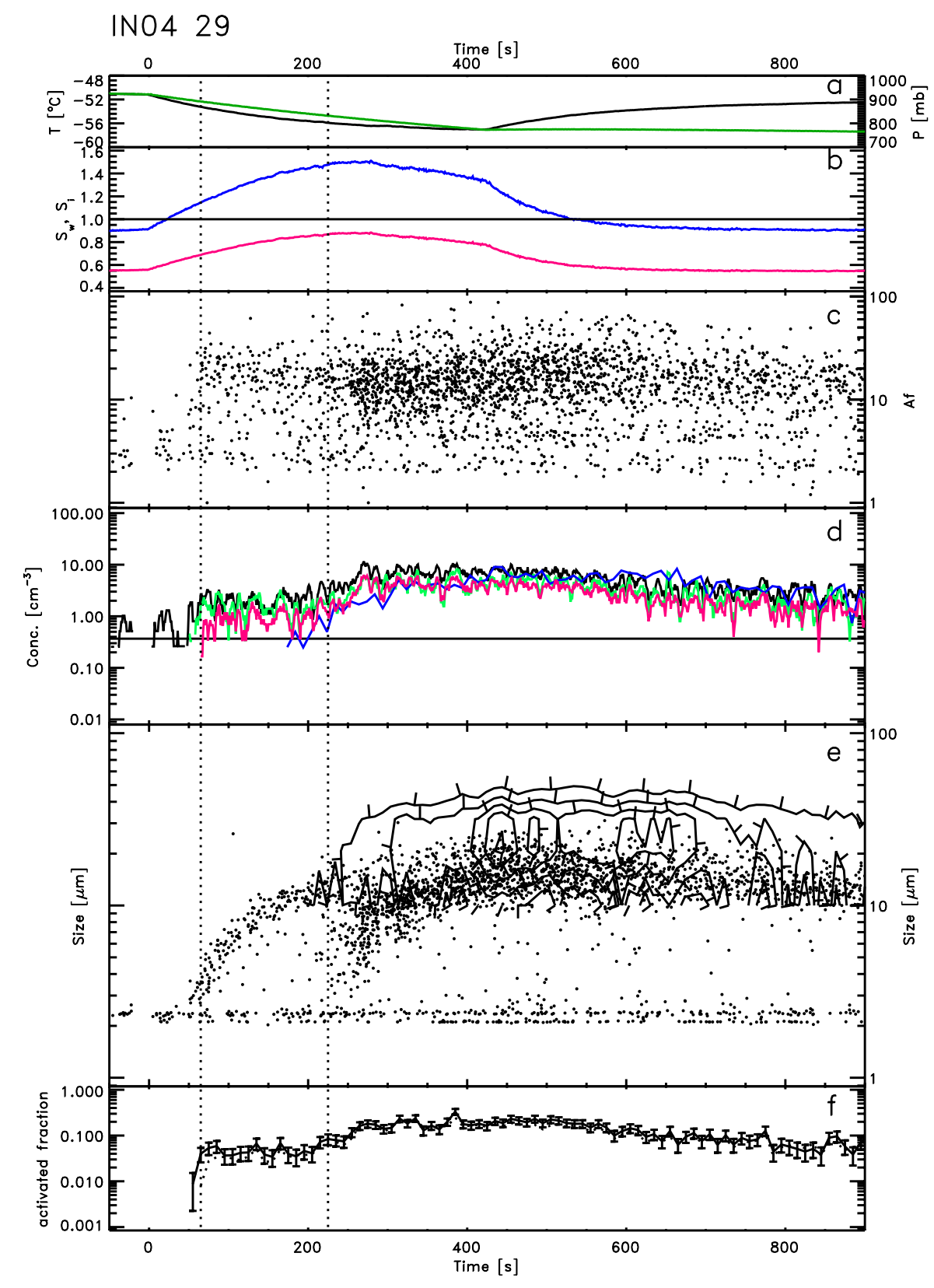

Fig. 1. Experiment IN04 29, AD1. Panel (a) shows the pressure forcing (green) and temperature change imposed in the AIDA cloud chamber (black). Panel (b) gives the saturation ratio with respect to water (red) and ice (blue) throughout the experiment. Panel (c) is a plot of the SID asphericity parameter, $A f$, each point represents a single particle measurement. In panel (d) various concentrations are depicted (5-s smoothing): The total SID concentration (black), the concentration of SID particles with $A f>12$ (non-spherical particles, green), the concentration of SID particles with "spherical diameter" $>3 \mu \mathrm{m}$ (red) and the CPI concentration (blue). Panel (e) shows single particle measurements of SID particle "spherical diameter" and a contour plot of the CPI size distribution (tickmarks indicate "downhill" direction). Panel (f) shows 10-s values of the activated fraction of desert dust (see text). Poisson counting errors are also shown. The solid line is the derived from particle concentrations for which $A f>12$ (corrected, see text) and the dotted line is the for particles with sizes greater than $3 \mu \mathrm{m}$.

with parcel modelling studies. The resulting ice formation activated about $10 \%$ of the aerosol (panel f). Again, CPI imagery for this experiment in Fig. 5 shows rosette-like habits, although the coldest temperature attained during this exper- iment was only $-32^{\circ} \mathrm{C}$. Bailey and Hallett (2004) find in laboratory crystal growth experiments that bullet rosettes are not formed at temperatures warmer than $-40^{\circ} \mathrm{C}$, therefore these crystals may be some other type of polycrystal habit. 


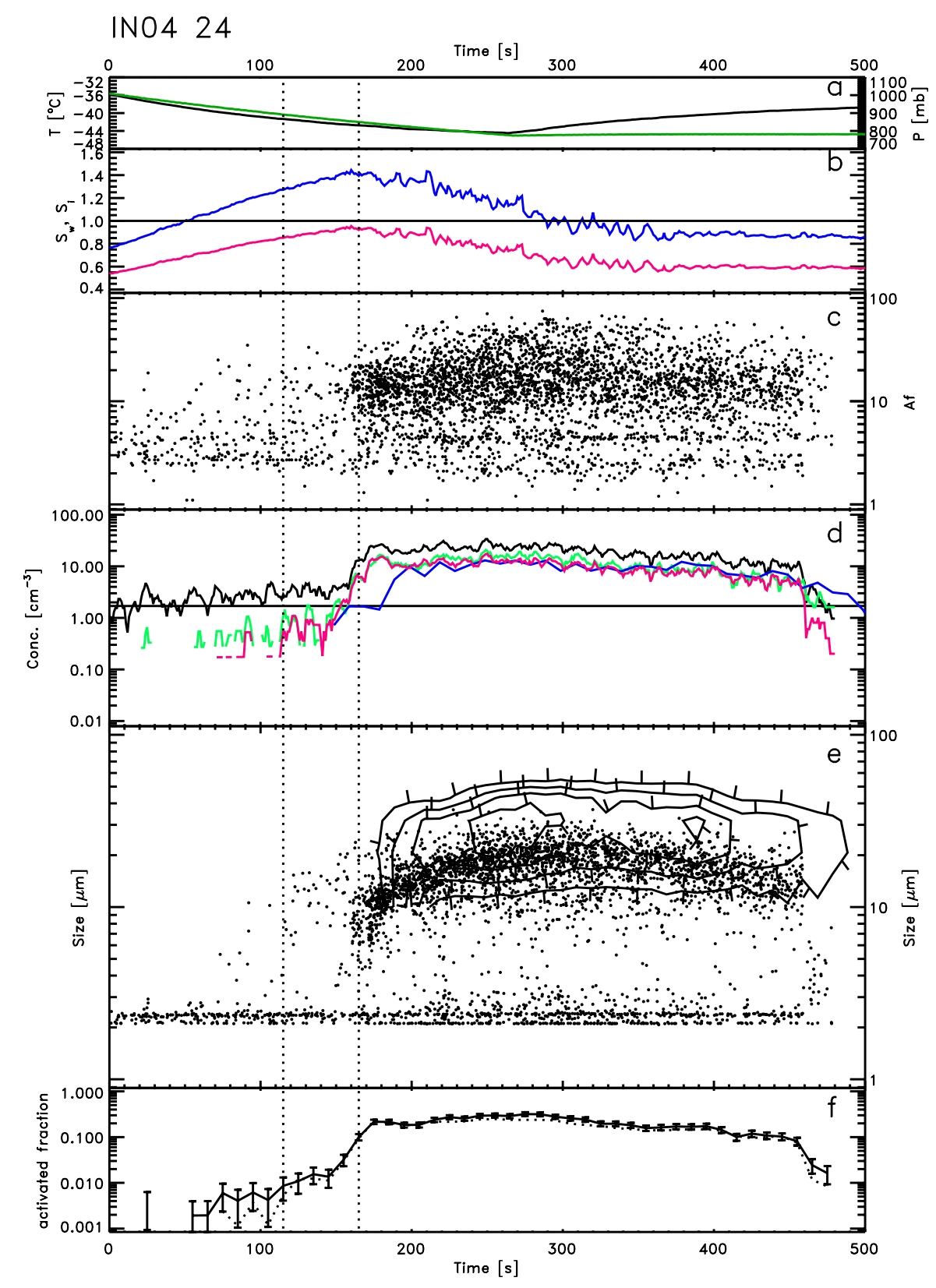

Fig. 2. Experiment IN04 24, AD1. Panel (a) shows the pressure forcing (green) and temperature change imposed in the AIDA cloud chamber (black). Panel (b) gives the saturation ratio with respect to water (red) and ice (blue) throughout the experiment. Panel (c) is a plot of the SID asphericity parameter, $A f$, each point represents a single particle measurement. In panel (d) various concentrations are depicted (5-s smoothing): The total SID concentration (black), the concentration of SID particles with $A f>12$ (non-spherical particles, green), the concentration of SID particles with "spherical diameter" $>3 \mu \mathrm{m}$ (red) and the CPI concentration (blue). Panel (e) shows single particle measurements of SID particle "spherical diameter" and a contour plot of the CPI size distribution (tickmarks indicate "downhill" direction). Panel (f) shows 10-s values of the activated fraction of desert dust (see text). Poisson counting errors are also shown. The solid line is the derived from particle concentrations for which $A f>12$ (corrected, see text) and the dotted line is the for particles with sizes greater than $3 \mu \mathrm{m}$.

Although, it should be noted that habit discrimination using the CPI is difficult for particles of this size.

Figure 4 results from run 31 which is part of the series of warmest runs presented here and uses the Saharan dust sam- ple (SD2). In this case the cooling is from $-19^{\circ} \mathrm{C}$ to $-26^{\circ} \mathrm{C}$ in $280 \mathrm{~s}$. Panel (e) shows the growth of particles starting at $40 \mathrm{~s}$ into the run. Panel (c) suggests that water droplets are present throughout the run until $470 \mathrm{~s}$. One unusual aspect 


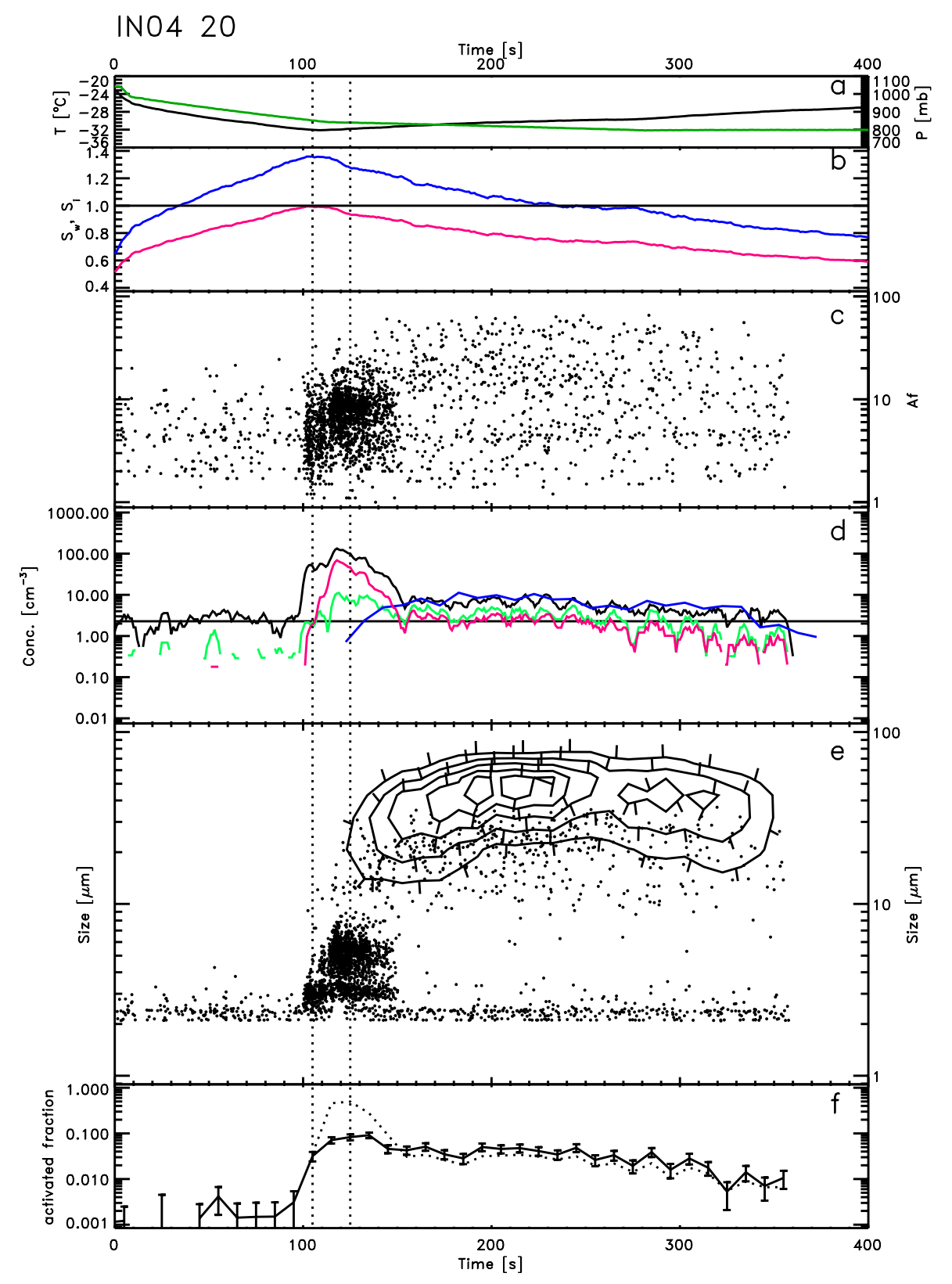

Fig. 3. Experiment IN04 20, AD1. Panel (a) shows the pressure forcing (green) and temperature change imposed in the AIDA cloud chamber (black). Panel (b) gives the saturation ratio with respect to water (red) and ice (blue) throughout the experiment. Panel (c) is a plot of the SID asphericity parameter, $A f$, each point represents a single particle measurement. In panel (d) various concentrations are depicted (5-s smoothing): The total SID concentration (black), the concentration of SID particles with $A f>12$ (non-spherical particles, green), the concentration of SID particles with "spherical diameter" $>3 \mu \mathrm{m}$ (red) and the CPI concentration (blue). Panel e shows single particle measurements of SID particle "spherical diameter" and a contour plot of the CPI size distribution (tickmarks indicate "downhill" direction). Panel (f) shows 10-s values of the activated fraction of desert dust (see text). Poisson counting errors are also shown. The solid line is the derived from particle concentrations for which $A f>12$ (corrected, see text) and the dotted line is the for particles with sizes greater than $3 \mu \mathrm{m}$.

of this series of runs is that the droplet concentration shows a peak near the beginning of the run and then falls to a plateau later. Comparison with the Welas instrument suggests that the SID is not seeing a large fraction of the water droplets. One suggestion for this discrepancy is that some water droplets are evaporating at these warm temperatures as they travel down the SID sample tube from the AIDA chamber. Nevertheless, we still observe that ice is formed at the 


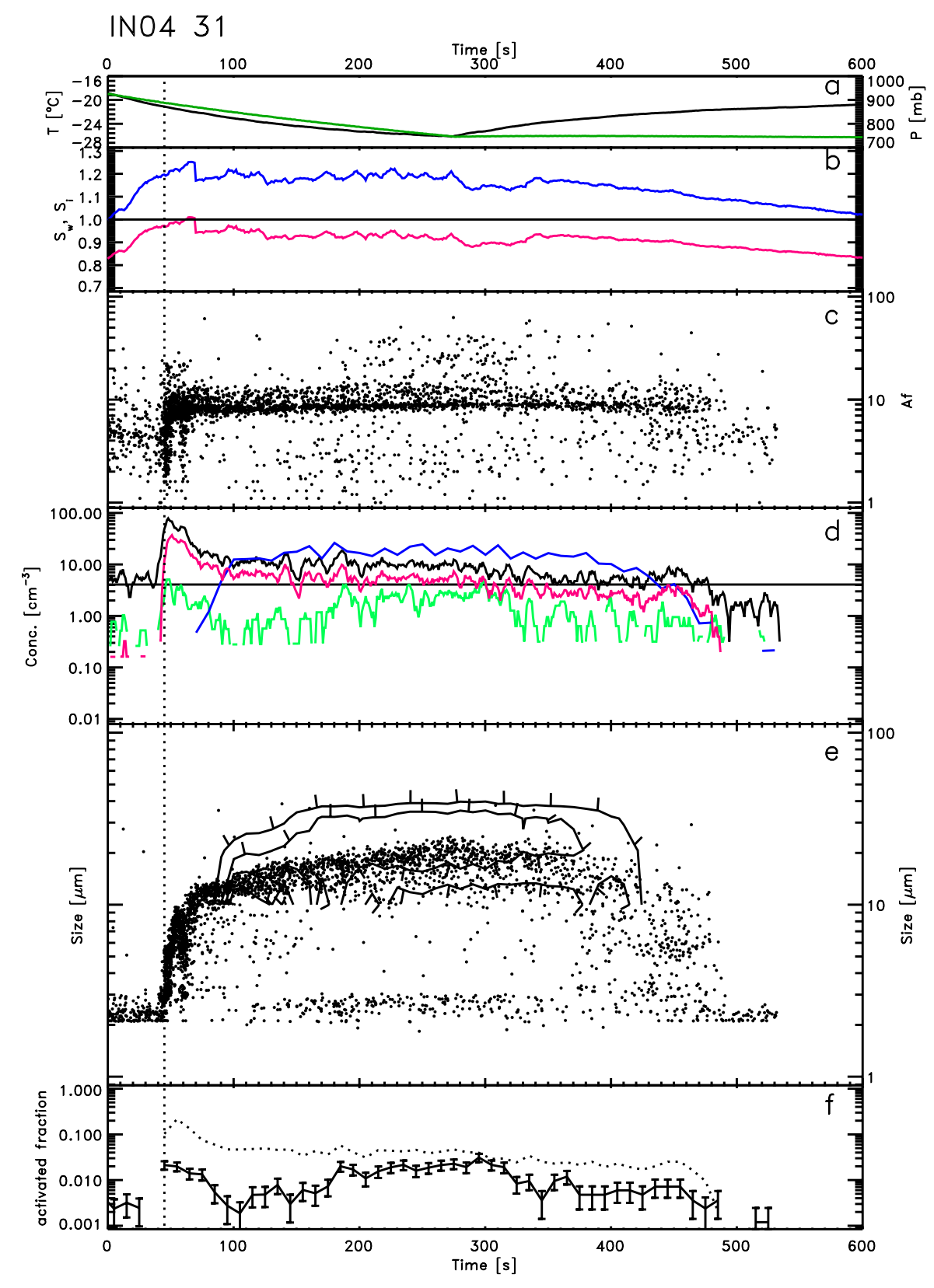

Fig. 4. Experiment IN04 31, SD2. Panel (a) shows the pressure forcing (green) and temperature change imposed in the AIDA cloud chamber (black). Panel (b) gives the saturation ratio with respect to water (red) and ice (blue) throughout the experiment. Panel (c) is a plot of the SID asphericity parameter, $A f$, each point represents a single particle measurement. In panel (d) various concentrations are depicted (5-s smoothing): The total SID concentration (black), the concentration of SID particles with $A f>12$ (non-spherical particles, green), the concentration of SID particles with "spherical diameter" $>3 \mu \mathrm{m}$ (red) and the CPI concentration (blue). Panel (e) shows single particle measurements of SID particle "spherical diameter" and a contour plot of the CPI size distribution (tickmarks indicate "downhill" direction). Panel (f) shows 10-s values of the activated fraction of desert dust (see text). Poisson counting errors are also shown. The solid line is the derived from particle concentrations for which $A f>12$ (corrected, see text) and the dotted line is the for particles with sizes greater than $3 \mu \mathrm{m}$.

same time as the droplets. Evidence for this comes from the CPI imagery which shows low concentrations of ice particles. In this series of experiments $(30,31,32)$, the aerosol concentrations were not available. Instead we used the peak droplet concentration from the Welas probe because experi- ments 18-21 showed that all of the aerosol became activated under the forcing conditions applied. CPI imagery in Fig. 5 for this experiment appears to show the coexistence of large droplets with irregular shaped ice crystals. 


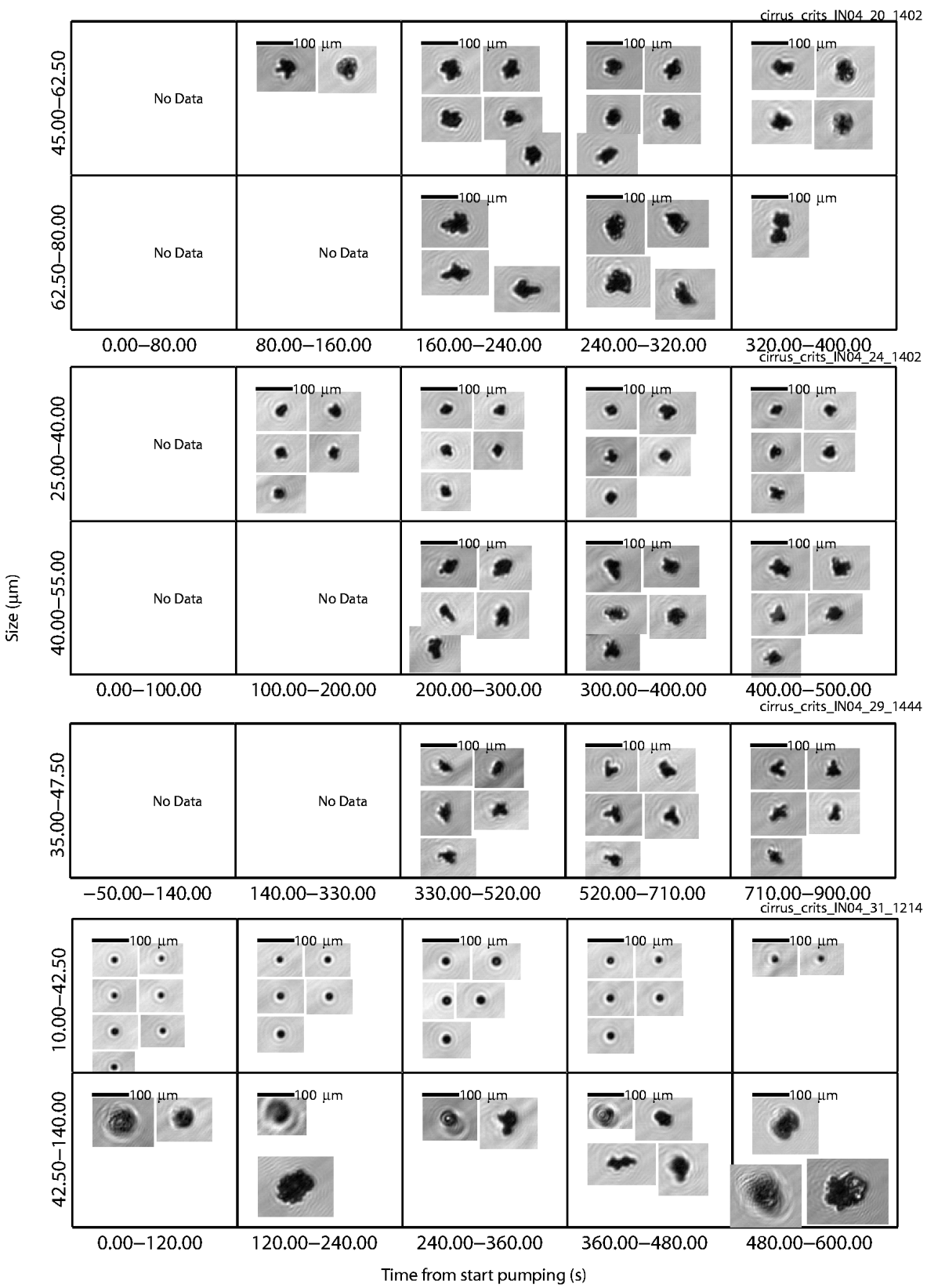

Fig. 5. Example CPI imagery from the four experiments shown in Figs. 1-4 (IN04 29(AD1), 24(AD1), 20(AD1), 31(SD2)). The x-axis represents time since pumping started and the values on the $y$-axis indicate the size range of particles considered.

\subsection{Synthesis}

As mentioned above we have identified when the activated fraction of aerosol exceeded $0.5 \%$ and $8 \%$. In practice, it was found that this choice of thresholds readily located the beginning of both the first and second nucleation event when two events were obvious. The first threshold is quite low considering the number of ice particles measured, and possibly subject to the effects of noise (experiment 32 requires only 2 particles to be determined as ice to exceed the first threshold), but as can be seen from Figs. 1-4 once the thresholds have been passed the concentrations remain above them while the pumping is continued. The results of this analysis are shown in Figs. 6 and 7. Figure 6 indicates the relative humidity and temperature associated with the points exceeding the $0.5 \%$ and $8 \%$ ice fraction thresholds. Three regions have been identified on the plot. In region I droplets were observed to form at the same time or prior to the formation of ice. The nucleation mechanism for these events is either condensation or homogeneous freezing for events close to $-40^{\circ} \mathrm{C}$. Region 
II contains the primary nucleation events that are the result of deposition nucleation and region III contains the secondary events that may be the result of a condensation freezing mode or a secondary deposition nucleation mode. Figure 7 shows the maximum fraction activated as a function of the temperature at which $0.5 \%$ were first activated.

\section{Discussion}

The experimental results can be divided into nucleation behaviour at temperatures warmer and colder than $-40^{\circ} \mathrm{C}$. For temperatures warmer than $-40^{\circ} \mathrm{C}$ denoted by region $\mathrm{I}$ in Fig. 6, the onset of ice nucleation activating aerosol fractions greater than $0.5 \%$ is coincident with the production of water droplets as the chamber reaches water saturation. Thus nucleation occurring in region I is via a condensation mode or homogeneous freezing for the experiments near $-40^{\circ} \mathrm{C}$. There is also the possibility that contact freezing is occurring, but we feel that the rate of production of ice that accompanies the droplet production is too rapid and the numbers of aerosol that have not been activated as droplets are too low for this mode to be important (e.g. Cotton and Field, 2002). However, the role of contact nucleation cannot be ruled out completely until detailed process studies with a parcel model have been carried out. Roberts and Hallett (1968) and Salam et al. (2006) also observed, using a static diffusion chamber and a continuous flow diffusion chamber, respectively, that kaolinite dust samples warmer than a critical temperature needed to be brought to water saturation before ice formed. However, in the Roberts and Hallett study, the coldest temperature for which this behavior was observed was $-28^{\circ} \mathrm{C}$. One exception in our results can be seen for experiment 32 at $-20^{\circ} \mathrm{C}$. This was the last experiment in that sequence and was started with low concentrations of dust. Inspection of the time series for this experiment shows that a spike in the concentration of particles larger than $3 \mu \mathrm{m}$ was observed close to the start of pumping. Following this, the concentrations fell back to the background levels and then eventually rose again, increasing the activated fraction to just below the $8 \%$ threshold while the humidity remained close to or at water saturation. This result seems anomalous but it may indicate that deposition nucleation is occurring at these relatively warm temperatures, as found by Roberts and Hallett (1968) and Bailey and Hallett (2002). This difference may be compositional, size related or a result of low nucleation efficiencies ( $<0.5 \%$ of the dust sample) that mean we are not able to observe the ice produced via deposition at these temperatures with the SID. The maximum activated fraction during the experiment for the region I nucleation events (Fig. 7) climbs by roughly a factor of 10 from 5 to $50 \%$ from -20 to $-40^{\circ} \mathrm{C}$, respectively. The high fractions seen for experiments 35-37 may result from additional ice forming via homogeneous nucleation at around $-40^{\circ} \mathrm{C}$.
In the warmer experiments (Temperature $>-40^{\circ} \mathrm{C}$ ) dust acted as cloud condensation nuclei. From Figs. 3-4 and results from the other experiments during this campaign it appears that approximately $50 \%$ or more of the dust formed droplets when the peak saturation was very close to or at water saturation. The humidity measurement uncertainty of $4 \%$ and the anticipated variability within the aerosol vessel of similar magnitude means that we cannot be certain of the actual humidity that activated the droplets on the dust particles. A modelling study of the activation of droplets on dust by Fan et al. (2005) obtains similar results for cases simulated with updrafts between $0.5-2 \mathrm{~m} \mathrm{~s}^{-1}$ and dust containing $1 \%$ by mass of soluble material. In the real atmosphere there is likely to be a mixture of aerosol types (e.g. Twohy and Poellot, 2005) including cloud condensation nuclei exhibiting excellent hygroscopicity. If the dust only acted as cloud condensation nuclei at significant supersaturations with respect to water then it is conceivable that the presence of soluble particles would compete with the dust and inhibit their activation as droplets as found in simulations carried out by Fan et al. (2005). If this occurred, then it is unlikely that ice would form as our results suggest that ice nucleation at these temperatures is dominated by condensation freezing.

The time series of particle concentration seen in Fig. 3 appears very similar to that observed in a wave cloud by Field et al. (2001): the initial leading water cloud disappears to leave an ice cloud tail. One important difference between the wave cloud and laboratory observations is that the water cloud in the wave cloud case was in existence for $\sim 5$ times longer than in the laboratory case. Cotton and Field (2002) were unable to reconcile existing ice nucleation schemes with the wave cloud observations, mainly because of the length of time that a parcel passing through the wave was held at water saturation. To match modelled and observed ice water content and concentrations they were forced to invoke an ice nucleation mode that was driven by droplet evaporation that had the effect of generating ice later in the lifetime of the cloud. In contrast, the AIDA results show that the ice formed at the same time as the droplets activated. It is hoped that parcel modelling of the AIDA results and aircraft observations will help to resolve this issue.

For temperatures colder than $-40^{\circ} \mathrm{C}$ Fig. 1 indicated that dual nucleation events were observed where ice formed at two distinct ice saturation ratios with a hiatus clearly visible, particularly in the 3rd and 4th runs of a series using the same aerosol sample. This behaviour was observed for both the Asian and Saharan desert dust samples. In Fig. 6, region II represents the primary activation during these experiments and region III marks the secondary nucleation event. In each of these series of experiments $(22-25,26-29,40-$ 42), the first expansion did not show a clear dual nucleation signature. However, the $>0.5 \%$ and $>8 \%$ activations for 22 , 26,40 appear to cluster well with the results from the later experiments in each series. Möhler et al. (2006) found that the fraction of aerosol that nucleates ice is dependent only on 


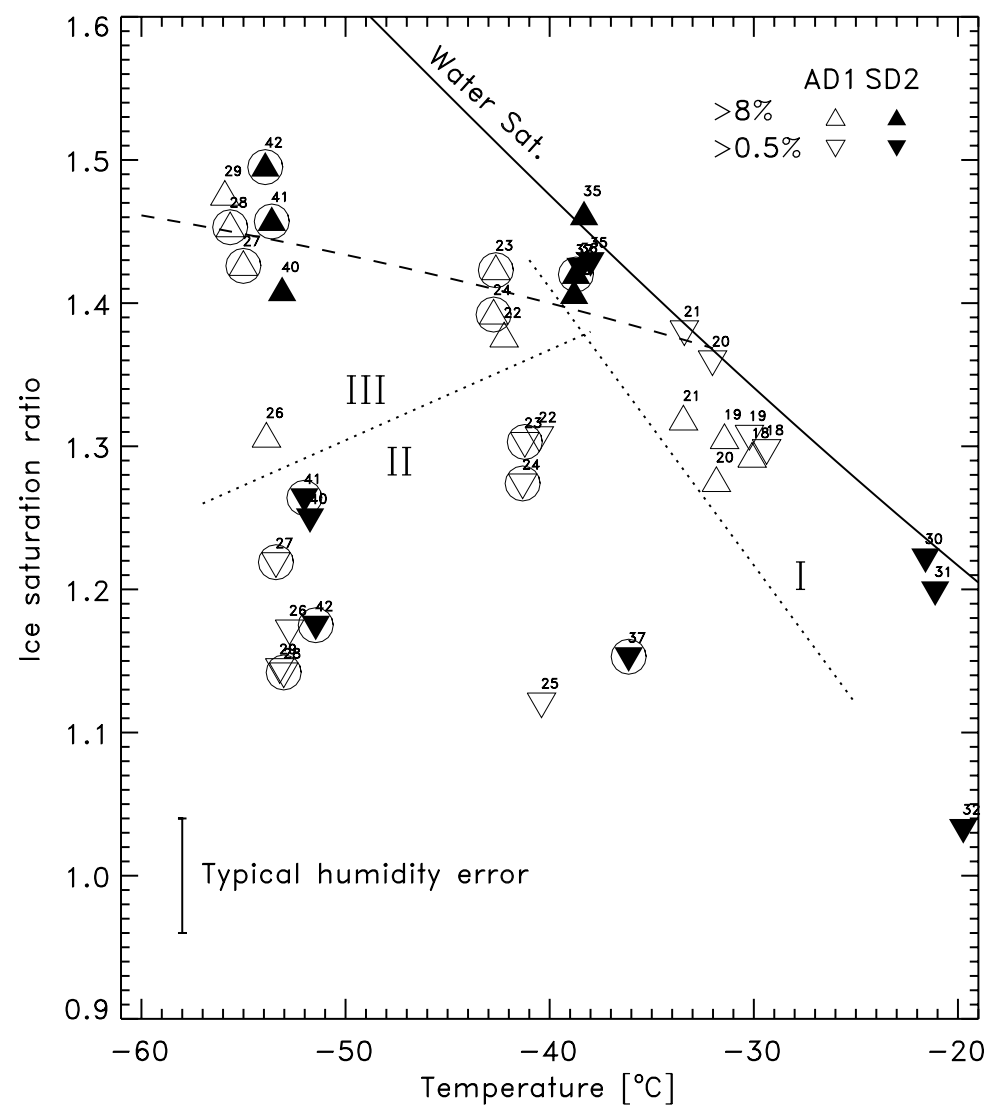

Fig. 6. Plot shows the ice saturation ratio and temperature at which ice nucleation was observed to begin. Open symbols are the results for the Asian desert dust sample (AD1), filled symbols are for the Saharan desert dust sample (SD2). The numbers adjacent to each symbol represent the experiment number (see Table 2). Downward pointing triangles denote when the fraction of aerosol forming ice crystals exceeded $0.5 \%$. Upward pointing triangles denote when the fraction of aerosol forming ice crystals exceeded $8 \%$. Circled symbols indicate when examination of the time series for the experiment clearly showed two distinct nucleation events. Region I: droplets form at the same time as ice (condensation freezing, or homogeneous freezing for temperatures close to $-40^{\circ} \mathrm{C}$. Region II: deposition nucleation. Region III: condensation freezing (see text). Dashed line indicates the results from Zuberi et al. (2002) for freezing of aqueous droplets $\left(\left(\mathrm{NH}_{4}\right)_{2} \mathrm{SO}_{4}{ }^{-}\right.$ $\mathrm{H}_{2} \mathrm{O}$ ) containing dust.

supersaturation with respect to ice and does not appear to be affected by the cooling rate. This suggests that if the first runs are carried out at slower pumping speeds then the dual nucleation may become apparent for the first expansion also, simply because this allows a longer temporal separation between the nucleation events. Alternatively, one could speculate that the initial activation of the dust as droplets redistributes soluble matter over the surface of the dust and that the clear observation of of two separate nucleation modes during subsequent experiments with the same sample is a manifestation of the effects of ageing or cloud processing on the nucleation ability of the dust. If this speculation were true there would be important implications for ice nucleation in the atmosphere.

The activation of $>0.5 \%$ of the aerosol occurs at an ice saturation ratio of 1.1 to 1.3 . Archuleta et al. (2005) find that $1 \%$ of $200 \mathrm{~nm}$ asian mineral dust activates with a ice saturation ratio of $\sim 1.35$. For the dust samples used here the mode in the particle size is approximately twice as large and bigger particles were also contained in the sample tested (see Sect. 3). The maximum activated fraction of desert dust following the secondary nucleation event appears constant and in the $20-40 \%$ range. The primary nucleation mode typically activated $<5 \%$ of the aerosol sample before the effects of the secondary mode became important. The ice saturation ratio at which the region II ice nucleation events occurred points to deposition nucleation as the likely formation mechanism. The situation is not so clear for the secondary mode which activates $>8 \%$ of the aerosol sample at ice saturation ratios between 1.35 and 1.5. These saturation ratios are close to what Zuberi et al. (2002) obtained for dust samples immersed in aqueous droplets $\left(\left(\mathrm{NH}_{4}\right)_{2} \mathrm{SO}_{4}-\mathrm{H}_{2} \mathrm{O}, 10\right.$ $50 \mu \mathrm{m}$ in size). In this case, no droplets were observed with the SID, but Archuleta et al. (2005) suggest that condensation on hydrophillic sites may be important at these temperatures and humidities. Analysis of bulk dust samples used 


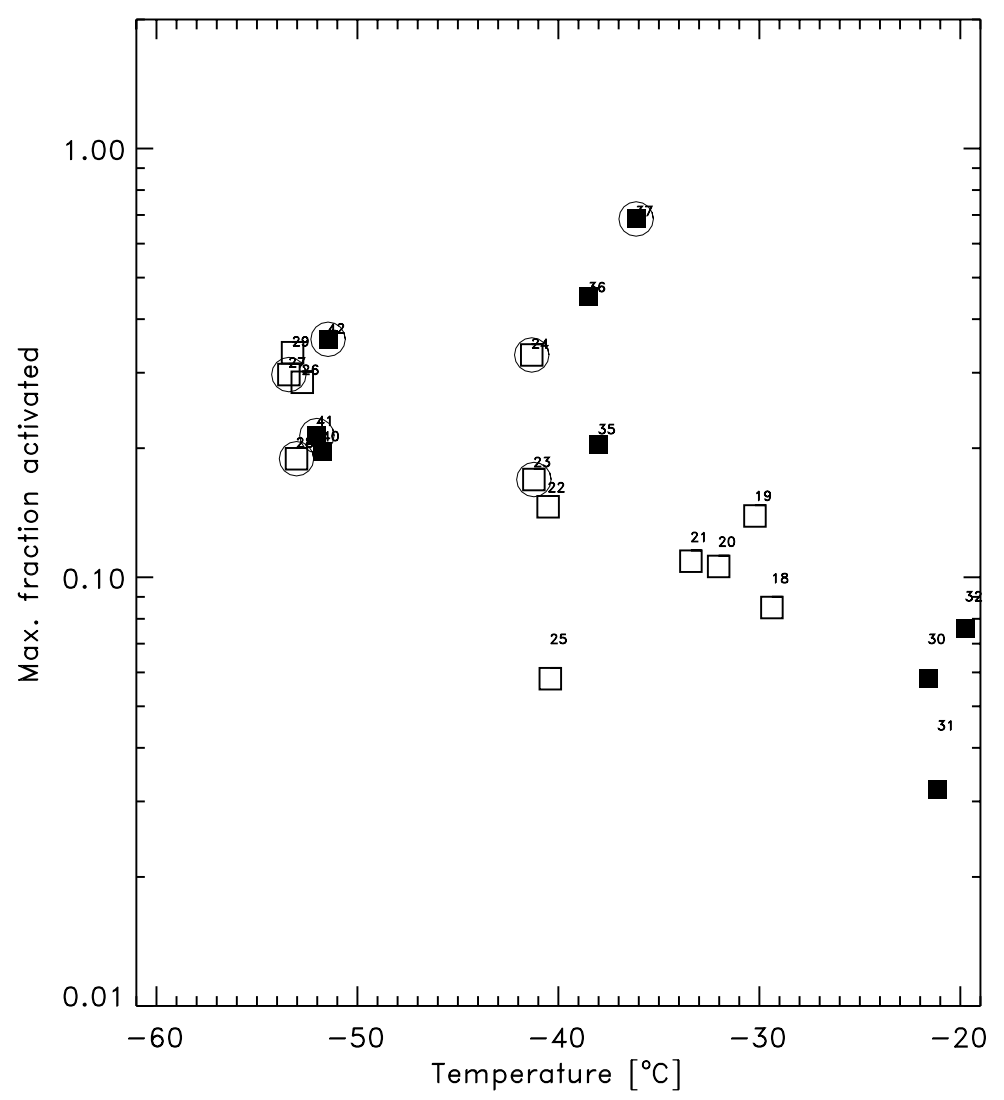

Fig. 7. This plot shows the maximum fraction of aerosol (10-s) activated to form ice as a function of temperature when the fraction exceeded $0.5 \%$. Open symbols are the results for the Asian desert dust sample (AD1), filled symbols are for the Saharan desert dust sample (SD2). The numbers adjacent to each symbol represent the experiment number (see Table 2). Circled symbols indicate when examination of the time series for the experiment clearly showed two distinct nucleation events.

in these experiments showed that $<1 \%$ by mass was made up of soluble material. We can speculate that if the soluble material is mainly found in surface coatings then the fraction of soluble material on the smaller particles used in these experiments is likely to be greater because the surface area to volume ratio is inversely proportional to particle size. Therefore, although we cannot definitely dismiss the idea that the secondary nucleation events (region III) represent a further deposition nucleation mode we can allude to the presence of soluble material in the bulk sample and the good agreement with the Zuberi et al. (2002) results to infer that is it likely that a condensation freezing mode is acting in region III. Future experiments should aim to analyse the ice crystal residuals at different times during the experiments in order to test this assertion.

Roberts and Hallett (1968) also reported that preactivation of aerosol leads to ice production at lower saturation ratios. Over the course of a day the aerosol samples in the AIDA chamber are cycled a number of times up to water saturation and then back to just below ice saturation. Unfortunately it is difficult to assess the fraction of nuclei lost to sedimentation that formed ice during a previous expansion. If it is assumed that the aerosol that activated ice crystals are not lost via sedimentation and participate in subsequent expansions, then the two series of expansions (26-29, $40-42$, Fig. 6) colder than $-50^{\circ} \mathrm{C}$ indicate that the condensation freezing requires higher humidity on each subsequent run. However, it should be borne in mind that the observed change in humidity at which the immersion freezing occurs is of a similar magnitude to the measurement uncertainty and could also be influenced by systematic errors due to detection time at different cooling rates (see Sect. 5.1).

The dual nucleation behaviour presented in Figs. 1 and 2 and evident in many of the experiments performed means that it is difficult to simply assign a bulk mineral dust sample with a nucleation rate. Therefore the nucleation rate parameterization approach that worked successfully in Möhler et al. (2006) for deposition nucleation at colder temperatures would only apply to the primary nucleation seen in region II of Fig. 6 and would have to be limited to nucleating a maximum of $\sim 5 \%$ of the dust. For the higher humidities another nucleation scheme representing condensation nucleation on 
the same aerosol species would need to be implemented. As Archuleta et al. (2005) show, there is at least a size dependence that needs to be taken into account and perhaps the dual nucleation represents a variation in the aerosols internal mixture of soluble to insoluble material that is correlated with size. Future work needs to include the capture and analysis of ice crystal residuals that form at different saturation ratios.

\section{Conclusions}

Two desert dust samples (modal diameter $0.3-0.5 \mu \mathrm{m}$ ) from the Sahara and Asia were used in ice nucleation experiments between $-20^{\circ} \mathrm{C}$ and $-55^{\circ} \mathrm{C}$ in the AIDA cloud chamber. Very similar behaviour was observed for both dust samples. We observed dual nucleation events during single expansions at temperatures colder than $-40^{\circ} \mathrm{C}$. The primary nucleation event is likely to be deposition nucleation, but the secondary event is either a further deposition mode exhibited by particles of different sizes or mineralogical/chemical composition or a condensation mode facilitated by the presence of soluble material on the desert dust. At temperatures warmer than $-40^{\circ} \mathrm{C}$ droplets were formed before and at the same time as ice crystals were formed, presumably via a condensation freezing mode and generally no deposition mode was observed. At temperatures close to $-40^{\circ} \mathrm{C}$ when droplet were activated, the high fractions of ice formed suggest that homogeneous ice nucleation dominated. The maximum activated fraction of the desert dust sample forming ice varied from $\sim 5-10 \%$ at $-20^{\circ} \mathrm{C}$ to $20-40 \%$ at temperatures colder than $-40^{\circ} \mathrm{C}$.

Acknowledgements. We gratefully acknowledge the support of AIDA staff members R. Buschbacher, T. Chudy, E. Kranz, G. Scheurig and S. Vogt for support during the campaigns. We thank L. Schütz (Univ. Mainz, Germany) for supplying the Asian dust sample, K. Megahed for supplying the Saharan dust samples and C. Adelhelm (IMF I, Forschungszentrum Karlsruhe) for XRF analysis of the mineral dust samples. We also thank E. Hirst (Univ. Hertfordshire, England) for making modifications to SID to allow its use at AIDA. Finally, we thank the two anonymous referees whose comments helped improve this manuscript.

Edited by: R. Volkamer

\section{References}

Archuleta, C. M., DeMott, P. J., and Kreidenweis, S. M.: Ice nucleation by surrogates for atmospheric mineral dust/sulfate particles at cirrus temperatures. Atmos. Chem. Phys., 5, 3391-3436, 2005, http://www.atmos-chem-phys.net/5/3391/2005/.

Bailey, M. and Hallett, J.: Nucleation effects on the habit of vapour grown ice crystals from -18 to $-42^{\circ} \mathrm{C}$ Quart. J. Royal Meteorol. Soc., 128, 1461-1483, 2002
Bailey, M. and Hallett, J.: Growth rates and habits of ice crystals between -20 degrees and $-70^{\circ} \mathrm{C}$, J. Atmos. Sci., 61(5), 514544, 2004.

Cantrell, W. and Heymsfield, A. J.: Production of ice in tropospheric clouds - A review, Bull. Am. Meteorol. Soc., 86(6), 795807, 2005.

Cotton, R. J. and Field, P. R.: Ice nucleation characteristics of an isolated wave cloud, Q. J. Roy. Meteorol. Soc., 128, 2417-2437, 2002.

Cziczo, D. J., Murphy, D. M., Hudson, P. K., and Thomson, D. S.: Single particle measurements of the chemical composition of cirrus ice residue during CRYSTAL-FACE, J. Geophys. Res., 109(D4), D04201, doi:10.1029/2003JD004032, 2004.

DeMott, P. J., Sassen, K., Poellot, M. R., Baumgardner, D., Rogers, D. C., Brooks, S. D., Prenni, A. J., and Kreidenweis, S. M.: African dust aerosols as atmospheric ice nuclei Geophys. Res. Lett., 30(14), 1732, doi:10.1029/2003GL017410, 2003.

Durant, A. J. and Shaw, R. A.: Evaporation freezing by contact nucleation inside-out Geophys. Res. Lett., 32(20), L20814, doi:10.1029/2005GL024175, 2005.

Fan, S. M., Moxim, W. J., and Hiram, L.: Implications of droplet nucleation to mineral dust aerosol deposition and transport, Geophys. Res. Lett., 32, 10, L10805, doi:10.1029/2005GL022833, 2005.

Field, P. R., Cotton, R. J., Noone, K., et al.: Ice nucleation in orographic wave clouds: Measurements made during INTACC, Quart. J. Royal Meteorol. Soc., 127, 1493-1512, 2001.

Field, P. R., Hogan, R. J., Brown, P. R. A., Illingworth, A. J., Choularton, T. W., Kaye, P. H., Hirst, E., and Greenaway, R.: Simultaneous radar and aircraft observations of mixed-phase cloud at the $100 \mathrm{~m}$ scale, Quart. J. Royal Meteorol. Soc., 130, 18771904, 2004.

Gettelman, A., Fetzer, E. J., Eldering, A., and Irion, F. W.: The Global Distribution of Supersaturation in the Upper Troposphere from the Atmospheric Infrared Sounder, J. Climate, in press, 2006.

Hirst, E., Kaye, P. H., Greenaway, R. S., Field, P., and Johnson, D. W.: Discrimination of micrometre-sized ice and super-cooled droplets in mixed-phase cloud, Atmos. Env., 35, 33-47 2001.

Hung, H.-M., Malinowski, A., and Martin, S. T.: Kinetics of heterogeneous ice nucleation on the surfaces of mineral dust cores inserted into aqueous ammonium sulfate particles, J. Phys. Chem. A., 107, 1296-1306, 2003.

Isono, K., Komabayasi, M., and Ono, A.: The nature and origin of ice nuclei in the atmosphere, J. Meteor. Soc. Japan, 37, 211-233, 1959.

Jensen, E., Starr, D., and Toon, O. B.: Mission investigates tropical cirrus clouds, EOS, 85, 45-50, 2004.

Lohmann, U. and Feichter, J.: Global indirect aerosol effects: a review, Atmos. Chem. Phys., 5, 715-737, 2005, http://www.atmos-chem-phys.net/5/715/2005/.

Lohmann, U. and Kärcher, B.: First interactive simulations of cirrus clouds formed by homogeneous freezing in the ECHAM general circulation model, J. Geophys. Res., 107(D10), 4105, doi:10.1029/2001JD000767, 2002.

Möhler, O., Stetzer, O., Schaefers, S., Linke, C., Schnaiter, M., Tiede, R., Saathoff, H., Krämer, M., Mangold, A., Budz, P., Zink, P., Schreiner, J., Mauersberger, K., Haag, W., Kärcher, B., and Schurath, U.: Experimental investigation of homogeneous freez- 
ing of sulphuric acid particles in the aerosol chamber AIDA, Atmos. Chem. Phys., 3, 211-223, 2003, http://www.atmos-chem-phys.net/3/211/2003/.

Möhler, O., Benz, S., Saathoff, H., Connolly, P., Krämer, M., Mangold, A., Field, P., and Heymsfield, A.: Efficiency of the deposition mode of ice nucleation on mineral dust particles, Atmos. Chem. Phys., 6, 3007-3021, 2006,

http://www.atmos-chem-phys.net/6/3007/2006/.

Pruppacher, H. R. and Klett, D. J.: Microphysics of clouds and precipitation, Kluwer, Netherlands, 954pp., 1997.

Roberts, P. and Hallett, J.: A laboratory study of the ice nucleating properties of some mineral particulates, Quart. J. Roy. Meteorol. Soc., 94, 25-34, 1968.

Salam, A., Lohmann, U., Crenna, B., Lesins G., Klages, P., Rogers, D., Irani, R., MacGillivray, A., and Coffin, M.: Ice nucleation studies of mineral dust particles with a new continuous flow diffusion chamber, Aer. Sci. Tech., 40(2), 134-143, 2006.

Sassen, K., DeMott, P. J., Prospero, J. M., and Poellot, M. R.: Saharan dust storms and indirect aerosol effects on clouds: CRYSTAL-FACE results, Geophys. Res. Lett., 30(12), 1633, doi:10.1029/2003GL017371, 2003.
Stocker, T., Clarke, G. K. C., Le Treut, H., Lindzen, R. S., Meleshko, V. P., Mugara, R. K., Palmer, T. N., Pierrehumbert, R. T., Sellers, P. J., Trenberth, K. E., and Willebrand, J.: Physical Climate Processes and Feedbacks, Chapter 7 of Climate Change 2001: The Scientific Basis, edited by: Houghton, J. T., Ding, Y., Griggs, D. J., Noguer, M., van der Linden, P. J., Dai, X., Maskell, K., and Johnson, C. A., Cambridge University Press, Cambridge, UK, 2001.

Targino, A. C., Krejci, R., Noone K. J., and Glantz, P.: Single particle analysis of ice crystal residuals observed in orographic wave clouds over Scandinavia during INTACC experiment, Atmos. Chem. Phys., 6, 1977-1990, 2006,

http://www.atmos-chem-phys.net/6/1977/2006/.

Twohy, C. H. and Poellot, M. R.: Chemical characteristics of ice residual nuclei in anvil cirrus clouds: evidence for homogeneous and heterogeneous ice formation, Atmos. Chem. Phys., 5, 22892297, 2005, http://www.atmos-chem-phys.net/5/2289/2005/.

Vali, G.: Nucleation Terminology, Bull. Am. Meteorol. Soc., 66, 1426-1427, 1985.

Zuberi, B., Bertram, A. K., Cassa, C. A., Molina, L. T., and Molina, M. J.: Heterogeneous nucleation of ice in $\left(\mathrm{NH}_{4}\right)(2) \mathrm{SO}_{4}-\mathrm{H}_{2} \mathrm{O}$ particles with mineral dust immersions, Geophys. Res. Lett., 29(10) 1504, doi:10.1029/2001GL014289, 2002. 